\title{
EL QUIJOTE Y LA REALIDAD VIVA DE LAS ESPAÑAS: LA VISIÓN HISTÓRICA DE PEDRO BOSCH-GIMPERA
}

\author{
MANUEL LÓPEZ FORJAS \\ Universidad Autónoma de Madrid \\ manuel.lopezforjas@gmail.com
}

\section{INTRODUCCIÓN}

$\longrightarrow$

n la conmemoración del cuarto centenario tras la publicación de la segunda parte de El ingenioso hidalgo don Quijote de la Mancha, se considera indispensable recordar la interpretación de un personaje muy influyente en la Segunda República Española, que colaboró activamente desde la cátedra y el rectorado en la Universidad de Barcelona entre 1933 y 1939: el historiador, arqueólogo, abogado, político y pensador republicano catalán Pedro Bosch-Gimpera (1891-1974). Después de un fecundo periodo de formación que lo llevó desde Barcelona y Madrid hasta Berlín, Oxford y Heidelberg, a través de las carreras de Derecho, Filosofía y Letras y el Doctorado en Historia, el profesor Bosch-Gimpera fue un gran promotor de la cultura a partir de los museos pedagógicos y su presencia educativa desarrollando el espíritu de la Institución Libre de Enseñan$\mathrm{za}^{1}$. Su aporte al mundo intelectual continuó aun durante la guerra y se prolongó en su exilio en Guatemala y en su domicilio definitivo: México.

En este país ejerció un gran magisterio en la Universidad Nacional Autónoma de México, participando en la fundación del Instituto de Investigaciones Antropológicas. También se le recuerda con mucho aprecio en la Escuela Nacional de Antropología, donde impartió muchos cursos y permitió la apertura a nuevos conocimientos y nuevas brechas de investigación. Además, desde la capital mexicana continuó la lucha republicana a través de los medios literarios y periodísticos,

\footnotetext{
Conoció a Francisco Giner de los Ríos en el segundo año de los cursos de Doctorado que debían estudiarse en Madrid. Allí, Bosch-Gimpera valoró positivamente la labor pedagógica del filósofo malagueño y el espíritu de la Institución Libre de Enseñanza y gracias a su motivación, se decidió a pedir la pensión a la Junta de Ampliación de Estudios para ir a estudiar a Berlín (Bosch-Gimpera 1971: 82-85).
}

Edad de Oro, XXXIV (2015), pp. 69-84, ISSN: 0212-0429 - DOI http://dx.doi.org/10.15366/edadoro2015.34.004 
dirigiendo revistas como España Nueva y Cuadernos Americanos y colaborando con otras como Las Españas y La Nostra Revista. En el ámbito internacional, publicó en lengua inglesa y francesa sobre arqueología, antropología e historia, escribió varios artículos de carácter político para el suplemento del periódico francés Solidaridad Obrera y fue nombrado Director de la División de Filosofía y de Humanidades de la UNESCO.

Es en este conjunto de actividades culturales donde se ha podido rescatar sus reflexiones en materia de pensamiento político referentes a la realidad histórica de España, así como su propia lectura del Quijote dentro de ese marco. En una carta al historiador catalán Rafael Olivar Bertrand (quien le escribió en lengua catalana y Bosch-Gimpera contestó en castellano, excepto la postdata), el arqueólogo nacido en Barcelona reflexionaba sobre el papel de la ciencia histórica y el deber del historiador de rescatar no solo los documentos materiales, sino los valores que estos encubren. Esa ausencia la notaba en la mayoría de los historiadores españoles, con la excepción de su amigo Claudio Sánchez-Albornoz. Por este motivo, a pesar de reconocer que su especialidad era la Prehistoria y la Historia Antigua, le contó que su tiempo libre lo destinaba a escribir «algunos ensayos de interpretación de la historia de España» frente a la versión oficial (Bosch-Gimpera 1978: 18)².

Ante esta visión del pasado, escrita por los vencedores de la guerra civil y de alguna manera herederos de la oligarquía y el caciquismo decimonónicos y de principios del siglo XX, Pedro Bosch-Gimpera necesitaba combatir esa versión imperialista y antihumanista de la historia de España y de América que mitificaba a la España conservadora como salvadora y redentora de una sola historia llena de conquista, expansión, intolerancia (llamada «batalla contra la Anti-España») y de un catolicismo falso que reemplazaba la doctrina social del mensaje cristiano por el mero orden jerárquico de las estructuras de poder y el control de la conciencia de los «vasallos» y, necesariamente para permanecer dentro del territorio español, «feligreses». Esa versión oficial de España la llamó historia «ortodoxa», la cual suponía la realidad de España como un ente metafísico e inmutable; es decir, que usaba una concepción esencialista de ciertos datos empíricos bajo una interpretación parcial, no científica ni suficientemente documentada para justificar el nacionalismo del grupo que había ocupado el poder en 1939 (Bosch-Gimpera 1996a: 18).

En 1976, varios de esos artículos fueron recopilados y publicados en España en un pequeño libro que fue titulado como La España de todos. En 1981 la UNAM hizo una reedición aumentada llamada El problema de las Españas. Esta última fue reeditada en Málaga por la Editorial Algazara en 1996. Aunque los tres volúmenes constituyen un esfuerzo de archivo bastante destacable, muchos

2 Carta en respuesta a Rafael Olivar firmada en la ciudad de México el 4 de agosto de 1969. 
artículos en torno a la misma temática permanecen en las hemerotecas de las revistas y suplementos culturales. En este trabajo se pretende ofrecer una reconstrucción de algunas ideas clave presentes en una selección de textos que no han sido reeditados, en conjunto con algunos que aparecen en El problema de las Españas y que hacen referencia directa a la interpretación que tenía Bosch-Gimpera sobre el Quijote.

\section{ESPAÑA Y EUROPA}

En primer lugar, se puede afirmar que la verdadera España no es una unidad cerrada ni excluyente. En el ensayo España y Europa, Bosch-Gimpera (1996b: 98) destaca el sentido primordialmente ecuménico de la cultura española, es decir, la apertura al diálogo y a la recepción de ideas distintas a las propias, incluso opuestas, pero respetando la libertad del otro. Por otro lado, Mariano José de Larra había dicho que en España ser liberal era ser un exiliado en potencia ${ }^{3}$. Esta dinámica precisamente indica que a lo largo de la historia miles de españoles se han visto obligados, para salvar su vida, a salir de la península y adaptarse a todo tipo de condiciones, que por más cómodas que sean, nunca llenan absolutamente el clima del suelo natal.

La grandeza y la miseria del español a lo largo de la historia ha sido su capacidad para volverse un ciudadano del mundo. Además, hay un carácter de hospitalidad que proviene de la mezcla de los pueblos originarios que habitaron la península ibérica, incluso desde la prehistoria. Gracias a esta cualidad, ha sido posible la convivencia - a veces rígida, otras más llevadera- con otras culturas y su recepción; desde la influencia griega, la romanización, el cristianismo, el islamismo, los judíos y con ellos el rescate de la sabiduría de la Antigüedad y de Oriente. Por esta razón, no es posible admitir el sentido universalista del papel de Castilla en la configuración de España, como llegó a afirmar el propio José Ortega y Gasset ${ }^{4}$.

\footnotetext{
Esta frase la atribuye Vicente Llorens (1979: 17) a Mariano José de Larra, pero en la edición de los artículos completos de este último no se pudo localizar.

4 Para el filósofo madrileño, Castilla hizo a España y posteriormente la deshizo. Aunque no utilizó el concepto de «universal» e incluso trató de matizarlo al decir que incorporación, unificación y sometimiento no implicaban la aniquilación de las identidades colectivas más locales. Es más, solo atribuía la capacidad para hacer a España a Castilla o a Aragón, sin embargo a este reino le atribuía un gran apego a sus tradiciones peculiares y un cierto ruralismo (Ortega y Gasset 1921: $18,36,52$; se cita a propósito por la primera edición de la obra, aunque Bosch-Gimpera lo hace por las Obras Completas de 1946, donde el texto original no varía). Ortega pensaba que las otras comunidades no podrían haber constituido una nación y que en lugar de España, habría cientos de cantones aún en el siglo xx.
} 
Al contrario, Bosch-Gimpera defiende que son todos los pueblos de España los que han tenido las «inquietudes universales». Así se explica, de un modo no imperialista, la huella de los pueblos sobre todo andaluces en América o la filosofía de Francisco de Vitoria, quien buscó ejercer la justicia en el pleno corazón del imperio de Carlos V. Pero también estas influencias y repercusiones llegaron hasta Europa, en materia de ciencia, economía, teoría jurídica y en la cuestión social. Bosch-Gimpera coincide con la generación del Regeneracionismo español en su lectura de la historia, donde se ve a la España del siglo XV como la potencia cultural preponderante en Europa, antes de la decadencia. Sin embargo, esta grandeza cultural no se debió en absoluto a ninguna política real de Carlos V o de Felipe II, ni siquiera a los Reyes Católicos ${ }^{5}$. Más bien, fueron aquellas raíces ecuménicas las que permitieron el desarrollo intelectual, artístico, literario y científico mediante sendos procesos de adaptación que mantenían una cierta identidad originaria. Esta unidad, no política ni determinada, se vio ampliamente dañada por «el cáncer de las guerras civiles, impuesto a España por una dinastía que no se había identificado con el país» (Bosch-Gimpera 1996b: 101). ¿Qué pasó entre el siglo XVI y el XVII? Para explicarlo, nada mejor que la figura del Quijote:

Desde el siglo XVII es el Quijote el símbolo del pueblo español. Un hidalgo bueno y generoso, enloquecido por la lectura de novelas de aventuras caballerescas, que ya estaban fuera del ambiente contemporáneo y que, al tomárselas en serio, le lanzan a luchar contra los molinos de viento, a confundir aldeanas con princesas y a libertar galeotes. Lo es también Sancho que conserva su cordura pero que se ve envuelto en las desdichas de su amo, por fidelidad a él y por desconocimiento de la empresa a que se lanza. A España le metieron en la cabeza y le obligaron a luchar contra los molinos de viento del mundo, enloqueciéndola como a Don Quijote y desviando su generoso sentido de humanismo ecuménico. Cervantes, que había sido actor en alguna de las escenas brillantes y al que la gloria de los ideales generosos se le tornaron cárceles y miseria y que vivía en la encrucijada en que se iniciaba el descenso, supo crear, acaso inconscientemente, aquellos símbolos que eran el reflejo de su propia tragedia y de la de su país. (Bosch-Gimpera 1996b:102)

Esta es la primera referencia explícita que se ha podido encontrar del profesor Bosch-Gimpera hacia la figura del Quijote y su significado. No se limita a interpretaciones literarias o filológicas, ni siquiera admite el papel de la crítica literaria; sino que partiendo de un conocimiento histórico de la época de Cervantes, identifica los símbolos presentes en el disfraz de novela para describir cómo un hombre de su tiempo se dio cuenta del giro negativo que España estaba teniendo

Para demostrar que su argumento no se debía a una especie de reivindicación del regionalismo o nacionalismo catalán, cita esta misma idea del presidente de la Segunda República, Manuel Azaña, en su discurso del 27 de mayo de 1932 a favor del Estatuto de autonomía de Cataluña. 
al negar ese humanismo ecuménico. Esta visión de la vida permite no solo la tolerancia (que muchas veces roza la hipocresía) sino una verdadera vivencia en comunidad que salvaguarda las diferencias y reconoce y respeta la riqueza de la personalidad, tanto individual como colectiva. El concepto de humanismo ecuménico es, por más, interesante, debido a que contrasta ampliamente con la idea de un humanismo totalitario u orgánico que los profesores universitarios del franquismo diseñaron ${ }^{6}$. Sin llegar a sostener un determinismo histórico, ni una necesidad o continuidad de la política imperial de la época de Carlos V y Felipe II reflejada en el nacionalcatolicismo de la dictadura de Franco, sí reivindica que había una «verdadera» tradición del pueblo español cuya evolución natural fue interrumpida por una estructura ajena a su naturaleza (Bosch-Gimpera 1996a: 24).

El concepto de humanismo ecuménico, hasta donde se ha podido constatar, no aparece como tal hasta 1993, en el libro del filósofo polaco marxista Adam Schaff ${ }^{7}$. En el prólogo escrito por los españoles Juan García-Nieto París y José Gómez Caffarena, los autores subrayaban que la religiosidad cristiana, con arraigo en el cristianismo primitivo, tiene una «efectividad social renovadora, exigente de justicia (y contraria por ello a la inercia conservadora de las estructuras opresoras» (1993:11). Curiosamente, Schaff reconoce que Gómez Caffarena hablaba ya en 1987 de un «ecumenismo humanista» en su libro La entraña humanista del cristianismo; pero, más allá de las mismas preocupaciones intelectuales, no se encuentran en Bosch-Gimpera las mismas bases bibliográficas ni la misma tradición (constatable documentalmente) que siguió ese jesuita español.

Con esta precaución hecha, no deja de sorprender que el concepto de humanismo ecuménico de Schaff sea muy parecido al de Bosch-Gimpera, aunque el del catalán es muy anterior y es usado con otros fines. El polaco quería mostrar el pensamiento original de Marx, alejándolo de las interpretaciones dictatoriales y ortodoxas, a tal punto de considerarlo un verdadero humanismo. Creía, por tanto, que era posible articular los dos grandes humanismos, el cristiano (teocéntrico) y el socialista (antropocéntrico), para hacer frente a los problemas de la civilización contemporánea. Aunque admitía que se llegaba a un punto en el que sus caminos se desviaban, ese quiebre solo tenía consecuencias en la problemática sobre la trascendencia de la vida humana, en el más allá; lo cual no impedía hacer un paréntesis y apostar más por lo que los unía que por aquello que los separaba. El mismo uso de la palabra ecuménico, procedente de la tradición eclesiástica

\footnotetext{
$6 \quad$ Están los nombres de los juristas y catedráticos de derecho José Corts Grau, Torcuato Fernández Miranda, Luis Legaz Lacambra y Francisco Elías de Tejada como representantes de ese humanismo totalitario o democracia orgánica.

7 El libro se intitula precisamente Humanismo ecuménico. Al parecer, apareció en alemán el año anterior por la editorial Müller, en Salzburgo.
} 
cristiana, se debía en Schaff a su intención de comunicar a los creyentes sus ideas de la manera más cercana (1993: 87-91).

Américo Castro reconocía que Cervantes plasmaba el valor de las virtudes cristianas, no en un sentido ceremonial, sino basándose en el amor y el respeto hacia el otro, en la caridad y el perdón; pero fundamentalmente en el amor y la humildad (Castro 2002: 279, 287). De un modo bastante parecido, Bosch-Gimpera reconoce esa espiritualidad en Cervantes, más allá de relacionarlo o no con el erasmismo y un humanismo auténtico. Aunque tampoco hay citas explícitas de la teoría marxista, lo que lo haría coincidir con Schaff, es verdad que el concepto de superestructura remite automáticamente al autor de El capital; si bien es cierto que desde su propia etimología le agrega un matiz personal y original. Sin poder constatar a ciencia cierta su vinculación con el marxismo, sí es posible determinar la simpatía de Bosch-Gimpera con el socialismo, siempre y cuando se explique su significado. En un manifiesto publicado en México en 1968, el catalán se pronunció junto a varios intelectuales exiliados contra la ocupación soviética en Praga y recordaron que el socialismo debe llevar en su base la defensa y el reconocimiento de la dignidad humana, de la libertad y el respeto a la personalidad de todos los individuos y de las naciones, con una verdadera democracia que conceda una verdadera igualdad de oportunidades a las personas en el sentido económico, pero también socio-cultural (Bosch-Gimpera 1968: 2).

\section{De LA Libertad AL IMPERIO}

Quizás porque en la actualidad el debate se ha paralizado o difuminado, sin olvidarse ni enfriarse siquiera, parece que hablar hoy en día de la monarquía hispana o del imperio es más fácil y directo, aunque en realidad el asunto encierra muchas problemáticas aún. Resulta que hacia 1947 todavía se mostraba un cierto miedo para poner sobre la mesa los temas de la leyenda negra, del imperio español o del reinado de Felipe II, por la posibilidad de ser tachado de apologeta o detractor, de continuador del proyecto absolutista o negador de las glorias de España. Evocando sus años de formación en Barcelona, Bosch-Gimpera (1971: 70) recordó a un profesor que impartía la asignatura de Història d'Espanya llamado Inocencio de la Vallina. Él les ponía como libro de texto el Manual de Historia de Picatoste, el cual era obligatorio en la mayoría de los institutos españoles de segunda enseñanza. El propio Vallina en clase de declaraba admirador de Felipe II. Incluso las visiones que se presumían de imparciales, comenta Bosch-Gimpera, llegaban a exponerse en un pensamiento incompleto o velado, casi desenfocando el problema real. Como remedio, quizá gracias a los ojos de un exiliado a nueve mil kilómetros de distancia, abrió la invitación a tocar el tema con toda seriedad, sacando 
a la luz todos los aspectos disponibles, sin miedo de admiración o censura. Solo así se podría emitir un juicio más verosímil sobre los valores legítimos de España (empezando por afirmar o negar su existencia), ver qué es posible recuperar y reconstruir a partir de allí o qué hay que desechar y generar (incluso esto permitiría un nuevo diálogo con mayor amplitud entre los pueblos de España, con Portugal y con América).

De este modo, se logrará neutralizar el «peligro español» e ir más allá de la división recalcitrante entre la España liberal y la España reaccionaria o conservado$\mathrm{ra}$, donde cada una se desgasta por el monopolio de la autenticidad. Para el caso de Felipe II, recupera la reflexión presente en el libro Las dos Españas del portugués Fidelino de Figueiredo, el cual fue reeditado en México en 1944. Allí analiza cómo la política regalista o confesional de Felipe II no es una creación ex nihilo, sino que tienen raíces históricas perfectamente constatables desde la reconquista en Covadonga, con el espíritu de una «cruzada por la unidad religiosa y por la imposición de una sola norma política a toda España» (Bosch-Gimpera 1996e: 144). El resultado sería un Estado o forma de organización política intolerante, autoritaria, absoluta y totalitaria. Al ser algo artificial, esa estructura superpuesta o superestructura que asimiló la locura de la monarquía imperial no puede considerarse algo español. En realidad, lo que la derecha conservadora consideraba como una «cruzada» para el caso de la Reconquista, más bien fue una lucha estatal entre reinos y gobiernos sin distinción de razas o religiones; solo así se entienden las múltiples alianzas de los reyes «españoles» con los califas, como cuando Alfonso X llegó a reconocerse vasallo de un rey marroquí (Bosch-Gimpera 1996j: 64).

Incluso la idea de nación homogénea y única procede de la tradición francesa con el lema «una nación: una lengua, una ley, una bandera y un gobierno» (Carretero 1996: 52). En contraposición, en la tradición española se encontraba la pluralidad de los pueblos con diferentes costumbres, lenguas y gobiernos, pero con una voluntad de unidad que incluía a Portugal y se inclinaba más hacia un modo federado (Carretero 1952). Aun así, al hablar de estos pueblos, no es posible interpretarlos ni apelar a ellos en un sentido cerrado desde la perspectiva de Bosch-Gimpera. Ante el problema que planteó el ya aludido Ortega sobre las causas y los fines de vivir juntos, cuestionando su posibilidad, el profesor catalán respondía que, a diferencia del mínimo acuerdo existente en otros pueblos sobre sus rasgos comunitarios y de la realidad permanente de la vida cotidiana de cada pueblo, España no está completamente realizada. El resultado es el debate al que

\footnotetext{
8 La primera edición en español que se ha podido constatar fue hecha por el Instituto de Estudios Portugueses en 1933. Hay una edición en América hecha en 1936 por la Editorial Nascimento: Santiago de Chile. Bosch-Gimpera se refiere a la traducción de 1944 de Felipe Teixidor, México: Ediciones de San Ángel. Hay una edición más actual (2014) publicada en Pamplona: Ediciones Urgoiti.
} 
se refería otro político catalán, Nicolau d'Olwer, quien describía a esos pueblos entre «el deseo unión y la imposibilidad de amalgama». Si a esto se suman las luchas constantes contra las superestructuras estatales que han atentado contra la evolución natural de los pueblos, se pueden comprender los fracasos de unidad y los particularismos (Bosch-Gimpera 1996j: 62-63).

La llegada de Felipe II y su política fue algo más azaroso que providencial y no hizo más que sembrar «los gérmenes del desastre» que ya se hallaban en los Reyes Católicos con claridad. Sin embargo, Bosch-Gimpera (1996a: 51) reconoce que ni Isabel de Castilla ni Fernando de Aragón llegaron a crear una España única a través de la identidad castellana, sino que su política estableció un estado superpuesto a los gobiernos de los reinos, los cuales luchaban para mantener su propia autonomía y legislación anterior (a tal nivel que los habitantes de Aragón eran considerados extranjeros por los de Castilla). En contraparte de esa España imperial, la España liberal y auténtica está por construir, «liquidando la herencia del Imperio» y recuperando incluso el sentido de libertad de conciencia y que los cristianos en España sean verdaderamente cristianos, es decir, que puedan convivir con todos los otros españoles - mejor dicho, con las otras personas- en una relación cordial, sincera, fraterna, con sentimientos comunes.

La misma Castilla era víctima de los efectos de la superestructura y no su causa. Bosch-Gimpera (1996j: 67) reconoce, desde la tradición historiográfica catalana de Rovira i Virgili, Nicolau d'Olwer, Companys, Macià y Pi i Suñer, que el problema para el siglo XVI fue la llegada de los Austrias, no el pueblo de Castilla. A pesar de sus defectos, la España de la Segunda República intentó de verdad reorientar y reestructurar el camino, pero terminaría experimentando el mismo destino que el Caballero de la Triste Figura:

Quebró nuevas lanzas por la inteligencia, por la dignidad, por la libertad individual, en la gran aventura de restablecer la soberanía del espíritu. Trató de realizar la locura de don Quijote, librando galeotes y desfaciendo entuertos, combatiendo follones y malandrines y topó con los molinos de viento y con la Santa Hermandad guardadora del orden de los que han creído que España es solo de ellos. (Bosch-Gimpera, 1996e:146)

No se trata de una idealización del breve periodo que duró la República. Se asumen y se admiten sus errores, humanos después de todo, pero se quiere subrayar los valores en los que se fundaba: un proyecto que defendía la dignidad y la libertad individuales, pero rescatando también el sentido comunitario de la cultura española histórica; no la España que pudo haber sido, sino la que se fue construyendo mediante ese humanismo ecuménico, a pesar de aquellos que pretendían un humanismo imperial, que en el fondo de humanismo tenía muy poco o nada. En suma, constituía un bastión que había combatido una «casta privilegiada», 
entendida como superestructura estatal, originada desde los centuriones romanos, los consejos visigodos, los condes feudales, los nobles, los secretarios del Consejo de Indias, los inquisidores y sus familiares, los funcionarios de los Borbones, los aristócratas de la época de la Restauración y todos los funcionarios del Estado que defendían los bastiones de la alianza política entre la Iglesia española y la monarquía (Bosch-Gimpera 1996a: 42-44)․

\section{Cervantes en la encrucijada histórica y el QuiJote}

En un texto de 1948 publicado en Cuadernos Americanos, Bosch-Gimpera habló sobre "Cervantes y un momento crucial de la historia de España», donde explicó el sentido de las acciones de Don Quijote y de Sancho a partir de la vida de Miguel de Cervantes y el contexto histórico que vivió. De acuerdo con él, el libro no consiste en una mera reducción a modo de reflejo de la historia novelada, ni mucho menos se puede entender como una simple crítica social o política que denuncia determinados aspectos de la realidad. Más allá de estos factores, que sí están presentes, existe una conexión enorme con la vida misma de una persona y de todo un pueblo, que no estaba hecho sino en proceso constante de construcción. Una historia de fracasos, sí, pero más que eso de experiencias de las que se puede aprender:

El Quijote es el resultado de la vida de Cervantes, y de su experiencia. Por él desfilan todos los tipos que ha conocido, ya desde Argel, que adquieren viva realidad, espejo de la sociedad española, de sus miserias y sus dolores, crítica sutil e implacable en el envoltorio de una novela sin finalidad trascendental aparente. En él adquieren forma definitiva personajes que ya aparecen en obras anteriores y ha sido preparado y meditado durante largos años en las soledades de los caminos castellanos, en la vida agitada de Sevilla, en el abandono de la cárcel, después de los desengaños de la Corte. La redacción definitiva esperó largo tiempo hasta que Cervantes tuvo espacio para escribirlo, tranquilamente la primera parte, apresurando la segunda después de aparecer el falso Quijote de Avellaneda. (Bosch-Gimpera 1948: 160)

Cervantes vivió en un contexto cultural donde todavía se respiraba el esplendor del Renacimiento español y entonces, con la ampliación de la monarquía hispana, hubo un periodo en el que ese apogeo coincidió con el político; pero no se

9 Esta crítica, aunque parezca anacrónica, en el fondo es una respuesta a la identificación que se hacía entre el imperio romano y el imperio español en la época de Carlos V y Felipe II, llevada a cabo por historiadores como el propio Ramón Menéndez Pidal (1952) en su Introducción a la obra colectiva Historia de España. En ese texto Menéndez Pidal ofreció una crítica a la conferencia de Pedro Bosch-Gimpera. 
puede confundir uno con el otro. Sin embargo, la decadencia política (que aconteció primero) afectó en sumo grado las condiciones sociales que permitían el desarrollo de la filosofía, de la teoría política, de la ciencia y de la técnica. Curiosamente, el área de la pintura, la literatura, la música y las artes en general no se vio perjudicada, aunque no dejó de coincidir y verse afectada con los síntomas de la decadencia que se venían ya arrastrando, en sus orígenes, desde los Reyes Católicos. Esto se debe a que, según Bosch-Gimpera, estos no hicieron la unidad de los pueblos de España ni les permitieron las mismas posibilidades de igualdad y de ejercicio de sus capacidades. Incluso llegaron a ofuscar a los pueblos levantinos y de Cataluña, siendo esta última un «elemento perturbador de la política española al minar esta su constitución y desordenar su vida» (Bosch-Gimpera 1948:153).

Por su parte, Castilla recibió obviamente el impacto de un modo más cercano y se contagió de esa falta de reconocimiento de equivalencia entre unas fuerzas peninsulares y otras. La organización política de la Corte, basada en los Consejos, puso en práctica una continua diferencia de tratos entre los pueblos. En síntesis, lo que parecía una unidad consolidada con acuerdos de base, no era más que «un conglomerado de pueblos con multitud de problemas planteados y nunca resueltos» (Bosch-Gimpera 1948: 154). Mientras se mantenga esa diferencia de dignidades y tratos de un pueblo a otro y persistan las relaciones de sometimiento o disminución, no puede hablarse más que de una España determinada de dudosa legitimidad histórica. Debido a la percepción que tenía sobre la naturaleza democrática de los pueblos, cuestionaba con rigor la España de dogmas impuestos y exclusiones mediante la excomunión y la descalificación como traidor. Si la España futura no es construida por todos, en equidad de condiciones y derechos, entonces no será la España verdadera (Bosch-Gimpera 1996j: 65).

La postura llega a tal punto que atribuye la misma capacidad a Andalucía, o Cataluña o Portugal para haber podido construir a la España verdadera frente a las superestructuras imperiales. En este sentido, se sostiene que el Imperio o la estructura imperial hegemónica no es capaz de conciliar y articular los diferentes intereses de los pueblos sobre los que se sustenta, a pesar de extender - violentamente - una misma lengua, un mismo sistema educativo, ético y religioso. En una palabra, para Bosch-Gimpera esas superestructuras no fueron capaces de crear un Estado real ni mucho menos democrático. Una vez derribada la tesis de Menéndez Pidal de la translatio imperii y de la vertebración castellana según Ortega y Gasset, Bosch-Gimpera considera que la única salida es la integración federal que tenga en cuenta la decisión libre de los pueblos y su voluntad de articularse a través de un órgano superior; como una especie de Commonwealth que rescate la verdadera tradición de los pueblos hispánicos (Bosch-Gimpera 1996h: 78).

De la misma forma, califica al reinado de Carlos $\mathrm{V}$ como un paréntesis en la historia de España y lo describe como un emperador alemán más que como un 
gobernante español. Toda su estructura burocrática y de control ideológico constituyó el primer intento en la historia de un proyecto de totalitarismo, a través del absolutismo con la apariencia de trascendentalismo religioso (Bosch-Gimpera, 1996g: 108). Bajo el gobierno de Felipe II observa ya los síntomas graves de decadencia e incapacidad, con un Estado mal administrado y mal construido y un pueblo depauperado, una de cuyas familias dio a luz a Miguel de Cervantes.

Después de desilusionarse de su labor de soldado al ver que el rey no protegía a los cautivos, ni siquiera a los que habían derramado su sangre por sus empresas, Cervantes también fracasó en su intento de liberarlos y en su carrera literaria como dramaturgo. Después de ser humillado como burócrata y ver imposibilitada su idea de ir a las Indias, logró convivir con muchas personas y hacerse de una gran fortuna espiritual e intelectual y así fue madurando el plan de la «ficción aparente» que constituye El ingenioso hidalgo don Quijote de la Mancha, sin tener la oportunidad de llegar a ver la gloria de su creación. Así terminó también don Quijote, obligado a volver a la vida mezquina y vulgar de su aldea, pero también su escudero:

Sancho, el hombre del pueblo, que acabó por contagiarse de los ideales de su amo, también es vuelto a la realidad después de su ilusión de gobernar rectamente la ínsula Barataria. Es preciso dejarlo todo como está, comprender que los molinos de viento no son gigantes, dejar a los privilegiados en sus puestos, justamente o no, que la envidia ande suelta, que los cuadrilleros sean los dueños del campo de Castilla y aseguren el "orden". Someterse y vegetar. También Cervantes había querido desfacer entuertos y soñado con andanzas gloriosas y debió renunciar a estas y hundirse en la vulgaridad de la burocracia y dejar a los cautivos que habían padecido con él en sus prisiones sin que nadie se interesase por ellos. (Bosch-Gimpera 1948: 161)

Con esta relación, Bosch asocia de un modo original la vida de Cervantes con el destino de sus personajes, pero también con la vida española. Quizás no haya que verlo como una descripción objetiva y pesimista de la historia, sino como una oportunidad para reflexionar sobre la realidad viva de España que llegó también a América y cuyo proyecto continúa vigente, para pensar si esos valores hoy en día pueden recuperarse de alguna manera, si esa tradición alternativa al proyecto imperial tiene hoy algo que decir y si es capaz de entablar un diálogo cordial con la mitificada «otra España» o, mejor dicho, con los «otros españoles» que, si se presumen cristianos de verdad, no podrán negar la fuerza y la realidad de estos ideales que los españoles del humanismo ecuménico defendieron con su vida:

Pero enfermo, molido, desengañado, Cervantes escribe su Quijote. Quiere que no se olvide todo lo que ha visto. ¿Quién sabe? Muchos creerán que ha escrito un 
nuevo libro de caballerías para divertir a sus contemporáneos o los más maliciosos que se ha burlado de la afición de aquellos a las novelas de aventura. No importa. Allí está oculto en sus episodios el sentido profundo. Otros tiempos vendrán y otras gentes que sabrán entender. Alguien comprenderá que hay entuertos que desfacer, que la bondad, la compasión y el amor a los hombres no carecen de sentido. Y acaso España también, la España que Cervantes había visto salir con las luces del alba y tener que volver a encerrarse en la calma pueblerina, como don Quijote. (Bosch-Gimpera 1948:161)

Como en la novela, se propone buscar el sentido profundo y real de la España de Cervantes por debajo de la superestructura que ha sofocado a la verdadera tradición en construcción. De este modo, Bosch-Gimpera admite la división de dos Españas, una oficial que fue hecha con bases de otras tradiciones, como la germánica desde la monarquía visigótica leonesa y su expansión católica; $y$, por otro lado, el pueblo que ha sobrevivido y se ha basado en determinados valores incluso de orden ético y político. Si en la Edad Media se justificó la ortodoxia política y religiosa por parte de determinados reyes, más grande aún fue la cultura de los pueblos y la civilización de la otra España ${ }^{10}$. La tradición medieval y el Renacimiento estuvieron en contacto con el mundo exterior, de donde llegó el Imperio, pero también se alimentó la tradición anticesarista de libertad y de dignidad donde coloca a juristas como Francisco de Vitoria, Juan de Mariana, Fox Morcillo, Eiximenis y Gualbes (Bosch-Gimpera 1996g: 112). Esta continuidad le permite explicar las independencias americanas y las motivaciones serias de dichos levantamientos, pues tenía claro que Bolívar, Hidalgo y Sucre no podían provenir de la misma casta ni tradición que Torquemada y sus inquisidores (Bosch-Gimpera 1996c: 70-71).

\section{CONCLUSIÓN}

Más allá de la veracidad científica y estrictamente objetiva de la interpretación de determinados hechos históricos y de la política en los citados contextos, la intención fundamental de Bosch-Gimpera apunta hacia la oposición al franquismo desde el exilio en México en la segunda mitad del siglo xx. Si el sistema de la dictadura creó una mitología que se remontaba hasta los Reyes Católicos y hasta las monarquías medievales visigóticas, asturianas y leonesas, la idea era demostrar

10 De este modo, también reconcilia a España con las virtudes positivas de la civilización occidental en términos de democracia y libertades individuales y colectivas. Según Bosch-Gimpera, hay una cierta prefiguración de la democracia moderna en el Medievo traducida por las Cortes en donde había ya rasgos de un gobierno del pueblo, por el pueblo y para el pueblo (Bosch-Gimpera 1996d: 152). 
que esa descripción histórica solo era un instrumento de justificación del régimen Estado-Iglesia y del propio fascismo como un «súper-Estado» militar e ideológico. Al mismo tiempo, pretendía mostrar que el verdadero mensaje cristiano de paz, bondad, amor, sacrificio, dignidad humana y libertad no correspondía con el mensaje nacional-católico del régimen (Bosch-Gimpera 1996g: 106-107) ${ }^{11}$.

De alguna manera, para el catalán la Segunda República Española representaba ese humanismo ecuménico del Quijote. Al separar la Iglesia del Estado, no solo no emprendió persecuciones por ideas religiosas, sino que llegó a defender los derechos de culto incluso durante la Guerra Civil. En 1937 se creó la Comisaría de Cultos, que también Negrín proyectaría en 1938, y desde el Ministerio de Defensa Indalecio Prieto trataba de garantizar el respeto a las prácticas religiosas en los miembros del ejército creyentes e incluso llegó a eximirlos de la actividad bélica para canalizarlos a labores de apoyo en los servicios de salud. En Cataluña, desde el Departamento de Justicia (donde trabajaba el propio Bosch-Gimpera) tomaron distintas medidas para garantizar la libertad de cultos y el auxilio espiritual en las cárceles de la comunidad (Bosch-Gimpera 1996f: 124) ${ }^{12}$.

La visión histórica que ofreció Bosch-Gimpera está presente a lo largo de varios textos que se fueron alternando con sus aportes a los estudios de las raíces prehistóricas de la península ibérica, de los pueblos vascos e íberos, de la cerámica, etc. Y esta descripción de «La desviación normal del curso de la historia de España» (1954) no hace sino invitar a las nuevas generaciones, de ambos lados del Atlántico, a pensar si es posible rescatar del olvido esa tradición verdaderamente humanista y ponerla en práctica para el contexto actual, como don Quijote lo intentó:

Era el canto del cisne de un mundo que se derrumbaba. Incomprendido por sus contemporáneos y asimilado más tarde por algunos espíritus comunes, el mensaje profundo de la vida de Cervantes y de su Don Quijote es el símbolo de que se acompaña el fracaso de una empresa comenzada con el impulso de un pueblo joven, vigoroso y excepcionalmente dotado, mas sacrificado por objetivos imposibles y olvidando las labores esenciales. Así, la España de Felipe II —que no supo deducir las consecuencias de la victoria de Lepanto y no escuchó a Cervantes en su demanda de socorro para los esclavos de las prisiones de África- se obstinaba contra los Países Bajos e Inglaterra y lanzaba su armada a la derrota, como Don Quijote atacando a los molinos de viento. Por esas razones, entre otras, Don Quijote

11 Por esta razón, subraya el argumento de que la Reconquista fue en realidad una lucha por la expansión política que afectó a lo religioso de modo accidental, debido a que en los reinos cristianos o en los califatos, debajo de la superestructura los cristianos, moros y judíos convivían más en paz que en conflicto.

12 Este ensayo fue publicado originalmente en catalán en la ciudad de México en el diario dirigido por exiliados catalanes, Xaloc, con el título «El problema religiós a Espanya i la seva història» (Bosch-Gimpera 1969).

Edad de Oro, XXXIV (2015), pp. 69-84, ISSN: 0212-0429 
- disimulado en una novela de aventuras - es la obra maestra del genio castellano, símbolo de las virtudes y los defectos de su España. (Bosch-Gimpera, 1954: 2)

Evidentemente, se trata de un camino difícil, debido a que los diversos intentos frustrados de unificación política han perjudicado considerablemente la capacidad de coordinar las diferencias y consolidar realmente esa unidad orgánica superior. Frente al particularismo, fruto del individualismo hispánico debido a los problemas históricos, el reto es superar el autoritarismo y la idea de partir de moldes doctrinales que presuponen una unidad preexistente ya ni siquiera española, sino humana. Sin embargo, reconociendo la individualidad y la personalidad de los pueblos, se puede rescatar sus valores y reordenar sus diferencias particulares (Bosch-Gimpera 1996i: 137-141). Partir del individuo en sí mismo no resulta una operación contradictoria, puesto que en la tradición liberal española e iberoamericana la soberanía popular respeta al individuo y la riqueza de su personalidad, aun cuando se asocie en grupos o colectividades (siempre y cuando sea voluntariamente).

Recibido: 22/05/2015

Aceptado: 27/07/2015

\section{OBRAS CITADAS:}

BosCH-Gimpera, Pedro (1948). «Cervantes y un momento crucial de la historia de España». Cuadernos Americanos. México, año VII, 4, pp.152-161.

(1954). «La desviación normal del curso de la historia de España». Solidaridad Obrera. Suplemento, París, junio, 480-486, pp.1-3.

Bosch-Gimpera, Pedro et al. (1968). «Contra todos los imperialismos», México: texto impreso con registro 3/106567 de la Biblioteca Nacional de España. 2 hojas sueltas. Agosto.

Bosch-GimPera, Pedro (1969). «El problema religiós a Espanya i la seva història». Xaloc, 28, pp. 2-11.

(1971). La universitat i Catalunya. Barcelona: Edicions 62.

(1978). Correspondencia, 1969-1974, Barcelona: Aymá.

(1996a). «España. Texto de la lección inaugural del curso 1937-38 de la Universidad de Valencia» [1937]. El problema de las Españas, Málaga: Algazara, pp.17-54. (1996b), «España y Europa» [España Nueva, México, v. II, 16, 9 marzo 1946]. El problema de las Españas, Málaga, Algazara, pp. 98-103.

-(1996c). «Dos Españas» [Las Españas. Año I, 2, noviembre 29 de 1946]. El problema de las Españas. Málaga: Algazara, pp.70-73.

(1996d). «Cortes y democracia en España» [España Nueva, México D. F., 16 de marzo de 1947]. El problema de las Españas. Málaga: Algazara, pp. 152-156. 
Bosch-Gimpera, Pedro (1996e). «Todavía Felipe II y el imperio» [España Nueva, México, v. III, 75, 26 abril 1947]. El problema de las Españas, Málaga: Algazara, pp.143-146. (1996f). «El problema religioso en España» [España Nueva, México, v. III, 105-106, 31 diciembre 1947], El problema de las Españas. Málaga: Algazara, pp.115-128. (1996g). «El Imperio no es España» [La Nostra Revista, 15, México D. F., 1947]. El problema de las Españas. Málaga: Algazara, pp.104-114.

(1996h). «La lección del pasado» [Las Españas, núm. 8, México, Abril de 1948]. El problema de las Españas. Málaga: Algazara, pp. 74-79.

(1996i). «Particularismo y unidad» [España Nueva. México D. F., abril de 1948]. El problema de las Españas. Málaga: Algazara, pp. 137-142.

(1996j). «La España de todos» [«La España difícil e ininteligible», Revista Mexicana de Cultura. Suplemento cultural de El Nacional, V época, 29. México D. F., 17 de agosto de 1969]. El problema de las Españas, Málaga: Algazara, pp. 62-69.

CARretero, Anselmo (1952). Las nacionalidades españolas. México: Aquelarre. - (1996). «Prólogo» de La España de todos [firmado en la Ciudad de México en mayo de 1975]. El problema de las Españas. Málaga: Algazara, pp. 55-61.

Castro, Américo (2002). El pensamiento de Cervantes y otros estudios cervantinos. Obras reunidas. Vol. 1. Madrid: Trotta.

García-Nieto París, Juan, y Gómez Caffarena, José (1993). «Prólogo» a Adam Schaff, Humanismo ecuménico. Madrid: Trotta.

FigueIredo, Fidelino de (1944). Las dos Españas. Traducción de Felipe Teixidor. México: Ediciones de San Ángel.

LlORENS, Vicente (1979). Liberales y románticos: una emigración española en Inglaterra (1823-1834). Madrid: Castalia.

MENÉndez PidAl, Ramón (1952). «Introducción». Historia de España. Tomo I, I. España prerromana. Madrid: Espasa-Calpe.

Ortega y GasSET, José (1979). España Invertebrada. Bosquejo de algunos pensamientos históricos. Madrid: Calpe.

Schaff, Adam (1993). Humanismo ecuménico. Madrid: Trotta. 
El Quijote y la realidad viva de las Españas: la visión histórica de Pedro Bosch-Gimpera

Resumen: En este artículo se presenta la interpretación alternativa de la historia de España que desarrolló el historiador y arqueólogo mexicano-catalán Pedro Bosch-Gimpera, frente a las versiones oficiales de su tiempo. Se pretende mostrar cómo distinguió proyectada su propia visión del pasado a través de la obra de Cervantes y cómo el Quijote representa un humanismo ecuménico que se desarrolló en la Segunda República Española. El texto expone su tratamiento de distintos hitos de la historia de España, los cuales intenta desmitificar con respecto del uso político que se les dio principalmente durante la dictadura de Franco, pero también como una constante en los primeros treinta años del siglo xx.

Palabras clave: Pedro Bosch-Gimpera, Quijote, Cervantes, humanismo ecuménico, historia de España.

The Quixote and the alive reality of the Spains: the Pedro Bosch-Gimpera's historical vision

ABSTRACT: This article presents the alternative interpretation of the spanish history that the mexican-catalan archaeologist and historian Pedro Bosch-Gimpera developed; opposite to the official versions of his generation. It tries to show how he distinguished his own vision of the past projected through Cervantes'work and how the Quixote depicts an ecumenical humanism that was applied during the Second Spanish Republic. The text exposes his treatment of different hits of the Spanish history, which he tries to debunk in regard to the political utilization that they received mainly during the Franco's dictatorship, but also as a constant in the first thirty years of the $x x$ century.

Keywords: Pedro Bosch-Gimpera, Quixote, Cervantes, ecumenical humanism, history of Spain. 
TERESA DE JESÚS (1515-1582)

Guillermo Serés (Universidad Autónoma de Barcelona)

La imaginación de Santa Teresa: virtudes y desatinos de «la loca de la casa»....... 11

Ana Garriga EsPino (Universidad Autónoma de Madrid)

El desafío editorial de las cartas de Teresa de Jesús.

LeCTURAS REPUBLICANAS DEL QUIJOTE

RAQUEL ArIas (Universidad Autónoma de Madrid)

León Felipe alista a don Quijote en el bando republicano. 57

MANUEl LóPez ForJas (Universidad Autónoma de Madrid)

El Quijote y la realidad viva de las Españas: la visión histórica

de Pedro Bosch-Gimpera.

CArmen Madorrán Ayerra (Universidad Autónoma de Madrid)

El Quijote como utopía necesaria: la mirada de Adolfo Sánchez Vázquez 85

\section{OTROS TEMAS}

SònIA BoADAS (Universitat Autònoma de Barcelona)

Libros y librerías: la recepción de Commynes en España 101

Lucila Lobato Osorio (Universidad Nacional Autónoma de México)

La noticia de la muerte de Policisne de Boecia: expresiones de dolor en un libro inconcluso.

María Gutiérrez Padilla (Universidad Nacional Autónoma de México)

La escenografía en el teatro caballeresco 131

ADRIÁn FERnÁNDEZ (Université de Fribourg)

Dos entremeses «auditivos» y sus niveles: hacia un metateatro visual. 145

David González de la Higuera Garrido (Universidad Complutense de Madrid) La visión premonitoria de Alonso en El caballero de Olmedo:

otra recuperación de lo popular

Esther Fernández LóPEz (UNED)

Perseo en la comedia tardobarroca: Ignacio Ferrera y Pasqual 169

Manuel Piqueras Flores (Universidad Autónoma de Madrid)

De La hija de Celestina $a$ La ingeniosa Elena: estructura narrativa, género literario e interpolación 
Dagoberto CÁceres Agullar (Western University Canada)

Realismo incesante: desde Celestina hacia su recepción 201

TeXTOS INÉDITOS

Davinia Rodríguez Ortega (Universidad Pública de Navarra)

Auto sacramental del Juego del Hombre, de Luis Mejía de la Cerda:

edición crítica 


\section{EDAD DE ORO}

Revista de Filología Hispánica XXXIV

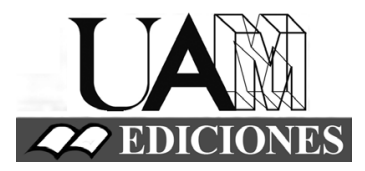




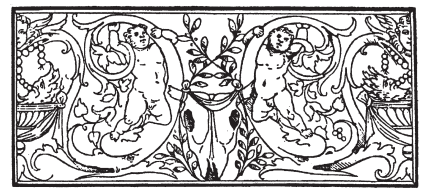

\section{Edad de Oro. Revista de Filología Hispánica}

ISSN: 0212-0429

Dirección:

Teodosio Fernández

Secretaría y edición:

José Ramón Trujillo

Comité científico internacional:

Carlos Alvar (Univ. de Ginebra)

Ignacio Arellano (Univ. de Navarra)

Javier Blasco (Univ. de Valladolid)

Alberto Blecua (UAB)

Jean Canavaggio (Univ. de París X)

Laura Dolfi (Univ. de Turín)

Aurora Egido (Univ. de Zaragoza)

Víctor García de la Concha (RAE)

Luciano García Lorenzo (CSIC)

Joaquín González Cuenca (Univ. de Castilla-

La Mancha)

Agustín de La Granja (Univ. de Granada)

Begoña López Bueno (Univ. de Sevilla)

Michel Moner (Univ. de Toulouse III)

Joan Oleza (Univ. de Valencia)

Alfonso Rey (Univ. de Santiago)

Lina Rodríguez Cacho (Univ. de Salamanca)

Leonardo Romero Tobar (Univ. de Zaragoza)

Aldo Ruffinatto (Univ. de Turín)

Lía Schwartz (City University of New York)
Redacción y admisión de originales:

Teodosio Fernández

Edad de Oro

Departamento de Filología Española

Universidad Autónoma de Madrid

28049 Madrid (España)

Tfno.: +0034914974090

correo: teodosio.fernandez@uam.es

Distribución, suscripción y venta:

Servicio de Publicaciones de la UAM

Universidad Autónoma de Madrid

28049 Madrid (España)

Intercambio de publicaciones:

Biblioteca de la Facultad de Filosofía y

Letras (UAM)

Universidad Autónoma de Madrid

28049 Madrid (España)

Han colaborado en este volumen:

Departamento de Filología Española (UAM)

Facultad de Filosofia y Letras (UAM)

Edad de Oro se recoge, entre otras, en las siguientes bases de datos: SCOPUS, MLA Database, HLAS, Latindex, PIO-Periodical Content Index, ISOC, Dialnet, MIAR, ERIH, DICE, Sumaris CBUC, Ulrich's. Se encuentra evaluada en CIRC: A; INRECH; MIAR difusión ICDS live: 9.977; SCImago Journal \& Country Rank: H Index 2, SJR 0,101, Q4; RESH índice de impacto: 0.041; ERIH: A INT1; Carhus Plus+ 2014: C. 